\title{
Accuracy and prevalence of defining characteristics of the diagnosis Impaired gas exchange in children
}

\author{
Acurácia e prevalência das características definidoras do diagnóstico Troca de gases \\ prejudicada em crianças
}

Alan Alves de Oliveira Araújo ${ }^{1}$, Lívia Maia Pascoal ${ }^{1}$, Paula Vitória Costa Gontijo ${ }^{1}$, Marcos Venícios de Oliveira Lopes $^{2}$, Marcelino Santos Neto ${ }^{1}$, Simony Fabíola Lopes Nunes ${ }^{1}$

\begin{abstract}
Objective: to evaluate the accuracy and to determine the prevalence of the defining characteristics of the nursing diagnosis Impaired gas exchange in children with respiratory diseases. Methods: cross-sectional study carried out with 236 children who were in the initial 48 hours of hospital admission. A questionnaire was used with sociodemographic data and physical examination of the respiratory system to identify the defining characteristics of the studied diagnosis. For the analysis of the accuracy, the sensitivity and specificity measures were calculated. Results: the diagnosis Impaired gas exchange was present in $21.6 \%$ of the sample and the most prevalent defining characteristics were dyspnea and tachycardia. Regarding the accuracy measures, the characteristics that presented high sensitivity values were dyspnea and abnormal respiratory pattern, while cyanosis, hypoxemia, and restlessness obtained high values of specificity. Conclusion: the characteristics that stood out both for the accuracy measures and for the prevalence were dyspnea and abnormal respiratory pattern.
\end{abstract}

Descriptors: Respiratory Tract Infections; Data Accuracy; Nursing Diagnosis; Child.

Objetivo: avaliar a acurácia e determinar a prevalência das características definidoras do diagnóstico de enfermagem Troca de gases prejudicada em crianças com doenças respiratórias. Métodos: estudo transversal realizado com 236 crianças que estavam nas 48 horas iniciais de internação hospitalar. Utilizou-se questionário com dados sociodemográficos e exame físico do sistema respiratório para identificação das características definidoras do diagnóstico estudado. Para análise da acurácia foram calculadas as medidas de sensibilidade e especificidade. Resultados: o diagnóstico Troca de gases prejudicada esteve presente em $21,6 \%$ da amostra e as características definidoras mais prevalentes foram Dispneia e Taquicardia. No que se refere às medidas de acurácia, as características que apresentaram altos valores de sensibilidade foram Dispneia e Padrão Respiratório anormal, enquanto Cianose, Hipoxemia e Inquietação obtiveram elevados valores de especificidade. Conclusão: as características que se destacaram tanto pelas medidas de acurácia quanto pela prevalência foram Dispneia e Padrão respiratório anormal.

Descritores: Infecções Respiratórias; Acurácia dos Dados; Diagnóstico de Enfermagem; Criança.

\footnotetext{
${ }^{1}$ Universidade Federal do Maranhão. Imperatriz, MA, Brazil.

${ }^{2}$ Universidade Federal do Ceará. Fortaleza, CE, Brazil.

Corresponding author: Paula Vitória Costa Gontijo

Av. da Universidade, s/n, Universidade Federal do Maranhão - Campus Bom Jesus, CEP: 65915240. Imperatriz, MA, Brazil. E-mail: paulagontijo17@hotmail.com
} 


\section{Introduction}

Respiratory diseases are the main cause of morbidity and mortality among children under five years of age, corresponding to an important public health problem. It is estimated that acute respiratory infections are responsible for $25.0 \%$ of pediatric consultations performed in hospital and outpatient settings ${ }^{(1)}$. In Brazil, respiratory diseases are considered the leading cause of death in childhood, with emphasis on lower respiratory tract infections such as pneumonia and bronchitis due to their increased risk of complications $^{(2)}$.

This may be related to unfavorable health conditions due to low income, inappropriate health and nutritional conditions, as well as an unexpected immune response $\mathrm{e}^{(3)}$. Among the main signs and symptoms that can be identified in children with respiratory infections, the presence of respiratory effort, such as intercostal drawing and nasal flaring, cyanosis, apnea, drowsiness, irritability, slow perfusion and tachycardia ${ }^{(1)}$. Therefore, it is important that nurses know these clinical manifestations so that they can more accurately infer the presence of nursing diagnoses related to the respiratory system ${ }^{(4)}$.

However, in some situations, knowledge about the pathophysiology of the disease associated with the nurse's diagnostic reasoning to recognize patterns in the signs and symptoms presented by the patient may not be sufficient to safely infer the presence of a nursing diagnosis. This is because some diagnoses, such as respiratory diagnoses, have common defining characteristics, such as dyspnea, or features that overlap with others, such as tachypnea. This fact may cause the nurse, in the practice of care, to have difficulty in defining the presence or absence of diagnosis, becoming a process of uncertainties with possibility of error $^{(5)}$.

A strategy to minimize the occurrence of an incorrect diagnostic inference is the use of tests related to the diagnostic accuracy. This type of approach contributes to identify the indicators that best define the patient's actual health status, showing a greater relevance and specificity. Therefore, studies of this nature contribute to improving the quality of nursing $\operatorname{care}^{(6)}$.

Among the respiratory nursing diagnoses of NANDA International, Inc. (NANDA-I), the Impaired gas exchange stands out, which was inserted in this taxonomy in the year 1980 and had its last review in 2017. In the course of reviews, the defining characteristic cyanosis was modified and for many years became restricted to neonates only. However, in 2015, this restriction was suppressed and in the most current version of 2017 this defining characteristic was excluded from the nursing diagnosis. Still in the edition of 2015, there were changes in the nomenclatures of the characteristics Visual disorders and Abnormal breathing, which happened to be designated as Visual disturbances and Abnormal respiratory pattern, respectively ${ }^{(7)}$.

The diagnosis Impaired gas exchange was recently listed among the nursing diagnoses that will be excluded from NANDA-I if new studies do not present a level of validating evidence. Because of this gap, it is necessary to conduct research that points to its relevance in clinical practice and contributes to its upda$\mathrm{te}^{(7)}$.

In view of the above, accuracy studies related to the nursing diagnosis Impaired gas exchange in children contribute to increase nursing knowledge by providing a more scientific basis, directing nursing interventions to the patient's real needs, and by favoring the advancement of the NANDA-I taxonomy. The research question that guided this study was: What is the prevalence and the accuracy measures of the defining characteristics of the nursing diagnosis Impaired gas exchange in children with respiratory diseases?

Thus, the objective of this study was to evaluate the accuracy and determine the prevalence of defining characteristics of the nursing diagnosis Impaired gas exchange in children with respiratory diseases. 


\section{Methods}

This is a cross-sectional study carried out with children who had respiratory diseases and who were admitted to the pediatric medical clinics of a Municipal Children's Hospital located in Maranhão state, Brazil. This health care institution responds to the spontaneous and referenced demand, and offers activities of low, medium and high complexity through emergency, outpatient and inpatient services.

The sample of this research consisted of 236 children of both sexes, aged between zero and five years, who were in the initial 48 hours of hospital admission due to respiratory problems. Children with motor dysfunction (eg, spinal muscular atrophy), neurological diseases (eg. cerebral palsy), heart disease (eg, tetralogy of Fallot) and renal diseases that could confuse the specific clinical picture of respiratory diseases were excluded. Patients were collected after hospital admission by consecutive sampling and the pre-established criteria were met.

Data were collected from July 2015 to April 2016 by a team of nursing students who were part of a research group on nursing diagnoses. All members of the collection team participated in a training, divided into three meetings lasting four hours each, conducted by the main researcher, to standardize data collection and minimize bias.

These data were obtained through anamnesis and physical examination through the application of a structured instrument used in a similar study ${ }^{(5)}$. This instrument contemplated the main clinical manifestations related to respiratory function and the defining characteristics of the diagnosis Impaired gas exchange, according to the NANDA-I taxonomy ${ }^{(7)}$. To assist in the evaluation of the defining characteristics, validated conceptual and operational definitions were used $^{(8)}$.

It is important to note that the characteristic dyspnea was evaluated differently from the conceptual definitions of other studies that define it as a subjective experience of respiratory discomfort, being considered qualitatively distinct with variable intensity ${ }^{(9)}$. Considering that the quantification of a subjective sensation such as "shortness of breath" is extremely difficult, especially in the pediatric population, in this study, we chose to evaluate dyspnea from the identification of signs of respiratory discomfort, such as nasal flaring and suprasternal, supraclavicular, subcostal, intercostal, and sternal abnormal chest retraction. This definition was validated for population with particularities similar to those that were part of the present investigation ${ }^{(8)}$.

Another point to be emphasized is that the defining characteristics of carbon dioxide level, abnormal arterial blood gas analysis, hypercapnia, hypoxia, and abnormal arterial $\mathrm{pH}$, which present concepts overlapping and can be assessed by means of gasometric tests, were not analyzed in this study. This is because this type of examination is not required for all children due to the clinical picture. Furthermore, the characteristics Confusion, Headache upon awakening and Visual disturbances were not included in the study because the age group of the evaluated population could interfere in the reliability of their evaluation.

Statistical analysis was performed using the statistical package Statistical Package for Social Sciences version 19.0 and software $\mathrm{R}$ version 2.12.1. The obtained data were arranged in spreadsheets of Excel ${ }^{\circledR}$ software and grouped in tables with frequency values, percentages and, accuracy measures.

We used the latent class analysis model with random effects to verify the sensitivity and specificity of the defining characteristics studied. This analysis is based on the assumption that an unobserved or latent variable (nursing diagnosis) determines the associations between the observable variables (defining characteristics). A model of two random classes of random effects was used to calculate the sensitivity and specificity values with the respective $95.0 \%$ confidence intervals ${ }^{(10)}$. In this type of model, the defining characteristics that have the worst performance are evaluated, first, by the statistical significance of the confidence intervals and, later, by the lower value ob- 
tained from the mean between sensitivity and specificity, being excluded from the data set ${ }^{(11)}$.

A latent class model with all the defining characteristics studied was initially created. Thereafter, the characteristics that presented sensitivity and specificity values lower than $50.0 \%$ or whose $95.0 \%$ confidence interval included this value were consecutively excluded. A new model was adjusted whenever a characteristic was excluded until the likelihood ratio $\left(G^{2}\right)$ and entropy indicated that the adjustment was adequate. It was necessary to adjust eight models until finding the final model. For all analyzes and tests applied, the significance level of $5 \%$ was adopted. A value greater than $50.0 \%$ and that did not include measures of sensitivity and specificity was established as a cutoff point for analysis of the accuracy. The prevalence of the nursing diagnosis was obtained by the overlap of the characteristics that were included in the final model ${ }^{(11)}$.

This study was approved by the Research Ethics Committee of the Federal University of Maranhão under opinion no. 935.110. The parents or legal guardians of the children agreed with their participation by signing the Informed Consent Form after receiving explanation about the objectives and relevance of this research.

\section{Results}

The majority of the children evaluated were males (62.2\%), with a mean age of 18.4 months (standard deviation: 16.5), and had pneumonia as the most frequent medical diagnosis (50.0\%). The data in Table 1 show that the defining characteristics with the highest prevalence were dyspnea (87.3\%), tachycardia (73.3\%), abnormal respiratory pattern (64.8\%) and abnormal skin color (63.1\%).

Table 2 shows the latent class initial model obtained using all the defining characteristics evaluated in this study. These results show that cyanosis was the defining characteristic that presented the highest specificity value (85.2\%), and dyspnea presented the best measure of sensitivity (81.4\%).

Table 1 - Prevalence of defining characteristics of the nursing diagnosis Impaired gas exchange

\begin{tabular}{lc}
\hline Variable & n (\%) \\
\hline Defining characteristics & \\
Dyspnea & $206(87.3)$ \\
Tachycardia & $173(73.3)$ \\
Abnormal respiratory pattern & $153(64.8)$ \\
Abnormal skin color & $149(63.1)$ \\
Irritability & $90(38.7)$ \\
Hypoxemia & $82(34.7)$ \\
Drowseness & $82(34.7)$ \\
Diaphoresis & $80(33.9)$ \\
Restlessness & $62(26.3)$ \\
Nasal flaring & $28(11.9)$ \\
Cyanosis & $12(4.1)$ \\
\hline
\end{tabular}

Table 2 - Description of the accuracy measures obtained from the initial latent class model for the defining characteristics of the diagnosis Impaired gas exchange in children with respiratory diseases

\begin{tabular}{|c|c|c|c|c|}
\hline $\begin{array}{l}\text { Defining } \\
\text { characteristics }\end{array}$ & $\begin{array}{c}\text { Sensitivity } \\
\text { (\%) }\end{array}$ & $95 \% \mathrm{CI}^{*}$ & $\begin{array}{c}\text { Specificity } \\
\text { (\%) }\end{array}$ & $95 \% \mathrm{CI}$ \\
\hline Restlessness & 18.9 & $12.5-25.6$ & 57.8 & $44.6-70.4$ \\
\hline Nasal flaring & 1.2 & $00.0-03.8$ & 65.0 & $51.2-77.5$ \\
\hline $\begin{array}{l}\text { Abnormal skin color } \\
\text { (pale, darkened) }\end{array}$ & 51.7 & $43.1-59.9$ & 11.9 & $02.1-20.5$ \\
\hline Diaphoresis & 18.2 & $11.6-25.4$ & 31.9 & $18.5-44.4$ \\
\hline Cyanosis & 0.6 & $00.0-02.2$ & 85.2 & $75.4-93.2$ \\
\hline Dyspnea & 81.4 & $75.2-87.4$ & - & $00.0-02.4$ \\
\hline Hypoxemia & 14.9 & $08.4-21.4$ & 22.1 & $08.4-34.1$ \\
\hline Irritability & 28.3 & $20.8-35.6$ & 40.5 & $27.9-52.9$ \\
\hline $\begin{array}{l}\text { Abnormal respirato- } \\
\text { ry pattern (frequen- } \\
\text { cy, rhythm, depth) }\end{array}$ & 51.8 & $43.7-60.0$ & 6.9 & $00.0-14.7$ \\
\hline Drowseness & 26.6 & $19.5-34.2$ & 47.5 & $34.9-59.5$ \\
\hline Tachycardia & 20.1 & $13.6-27.1$ & 59.0 & $45.8-71.8$ \\
\hline
\end{tabular}


The data presented in Table 3 correspond to the latent class final model with random effects whose adjustment was considered acceptable. Likelihood ratio: 18.13; Degree of freedom: $20 ; \mathrm{p}=0.578$ and entropy of 0.74 . The diagnosis Impaired gas exchange was identified in $21.6 \%$ of the sample and the characteristics that presented high values of accuracy (above 70.0\%) were dyspnea (Sensitivity: 99.9\%), abnormal respiratory pattern (Sensitivity: 99\%), cyanosis (Specificity: 100.0\%), Hypoxemia (Specificity: $81.7 \%$ ), and Restlessness (Specificity: 76.4\%).

Table 3 - Description of the accuracy measures for the defining characteristics of the diagnosis Impaired gas exchange in children with respiratory diseases

\begin{tabular}{|c|c|c|c|c|}
\hline $\begin{array}{l}\text { Defining } \\
\text { characteristics }\end{array}$ & $\begin{array}{c}\text { Sensitivity } \\
(\%)\end{array}$ & 95\% CI* & $\begin{array}{c}\text { Specificity } \\
\text { (\%) }\end{array}$ & $95 \%$ CI \\
\hline Restlessness & 36.3 & $22.8-52.2$ & 76.4 & $67.5-82.2$ \\
\hline Cyanosis & 1.9 & 00.0-98.9 & 100.0 & 99.9-100.0 \\
\hline Dyspnea & 99.9 & $98.9-100.0$ & 46.9 & $34.1-55.4$ \\
\hline Hypoxemia & 94.7 & 05.5-99.9 & 81.7 & 61.5-88.8 \\
\hline $\begin{array}{l}\text { Abnormal respiratory } \\
\text { pattern (frequency, } \\
\text { rhythm, depth) }\end{array}$ & 99.9 & $97.1-100.0$ & 44.8 & $32.1-53.9$ \\
\hline
\end{tabular}

\section{Discussion}

As limitations of this study, we highlight the target population that, at times, presented resistance or lack of interaction with the evaluators due to the young age and also to the fact that the collection was done by different researchers, which may have generated differences in evaluations, despite the fact that training was carried out to minimize the occurrence thereof.

The data obtained in this research will contribute both to strengthening the nursing diagnosis Impaired gas exchange in the taxonomy of NANDA-I and to facilitate its use in the practice of care for making the identification of respiratory signs and symptoms more accurate and favoring the diagnostic reasoning of the nurse. In addition, this study allowed us to iden- tify that the defining characteristic cyanosis is associated to the occurrence of this nursing diagnosis in children with respiratory infections, however, it was removed from the current edition of NANDA-I.

The prevalence of the nursing diagnosis Impaired gas exchange, found in the present study, diverged from another research ${ }^{(5)}$ also performed with children, which identified that diagnosis in $42.6 \%$ of the patients. This divergence of outcome may be related to the fact that although pneumonia was a medical diagnosis frequently identified in the present investigation, a significant portion of the sample also presented other types of milder respiratory infections. In contrast, in the aforementioned study, the majority of the sample presented pneumonia (85.3\%) as a medical diagnosis, which tends to be a respiratory disease that causes more negative repercussions on the functioning of the respiratory system. This fact may explain the divergence between the prevalence of the diagnosis Impaired gas exchange.

Regarding the characteristic tachycardia, the result found in the sample evaluated differs from another study ${ }^{(12)}$ performed with children with acute respiratory infection, whose frequency was $22.1 \%$. This divergence of result may be related to the most prevalent clinical conditions among the participants of this research, such as Dyspnea and Abnormal respiratory pattern, which cause greater physiological instability.

In this study, the characteristic Abnormal skin color was evaluated by the presence of hyperchromia or pallor ${ }^{(8)}$ and obtained a prevalence that was different from that identified by other authors, since it was observed in $15.0 \%$ of the children with acute respiratory infection evaluated ${ }^{(12)}$. Skin and mucosal acroma may occur due to the presence of small amounts of hemoglobin in the microcirculations. This alteration can manifest in the whole organism, but it is better evaluated in places where the blood vessels are near the surface, indicating hemodynamic compromise ${ }^{(7)}$. Neurogenic or hormonal stimuli, hypovolemia, or acidosis are situations that may cause vasoconstriction and contribute to the occurrence of the said characteris- 
tic ${ }^{(13)}$. Moreover, the presence of pathological processes, such as pneumonia, can lead to obstruction of the airways, causing retention of blood gases. Therefore, it is believed that such circumstances may justify the prevalence of the characteristic Abnormal skin color identified in the studied population ${ }^{(14)}$.

The characteristic dyspnea was the most prevalent in this study, and this result corroborates with another research conducted with children with acute respiratory infection in which it was present in $45.7 \%^{(12)}$ of the sample. Dyspnea is one of the major clinical manifestations resulting from respiratory tract infections. The presence of secretion in the capillary alveolar membrane causes the organism to increase pulmonary ventilation to compensate for the deficiency in gas exchange. This increase in ventilation occurs through increased respiratory frequency and depth. Dyspnea can be described by the patient as a subjective experience of respiratory discomfort, shortness of breath, or difficult breathing ${ }^{(15)}$. Furthermore, it can be evaluated objectively by the nurse for the identification of signs of respiratory discomfort causing changes in the normal respiratory pattern ${ }^{(9)}$. Regarding the accuracy measures, dyspnea had a high sensitivity in the present investigation, which diverges from another study in which this characteristic did not present a relevant percentage ${ }^{(5)}$.

For the abnormal respiratory pattern, the prevalence obtained in this study and the sensitivity value corroborate with another study, also performed with children with respiratory infection, which presented a high sensitivity (82.9\%) and the prevalence identified was $79.5 \%{ }^{(5)}$. The presence of this characteristic was determined indirectly by the following clinical manifestations: change in respiratory rhythm, manifested by changes in the periodicity of inspirations and expirations; respiratory rate, evaluated by the number of respiratory incursions according to the child's age range; and respiratory depth, characterized by the amplitude of respiratory incursions ${ }^{(13)}$. Increased respiratory frequency and depth may occur as an attempt by the body to combat elevated levels of carbon dio- xide and hydrogen ions in the blood, thereby functioning as a compensation mechanism to try to supply the oxygen flow to the body. These alterations may be associated with impairment of airflow due to obstruction caused by secretions retained in the airway, which is common in children with respiratory infection. This fact may explain the presence of the abnormal respiratory pattern in the evaluated children ${ }^{(5)}$.

Among the defining characteristics studied, the one with the highest specificity value was cyanosis. Similar results were found in a study carried out with children with acute respiratory infection, since the result was $99.8 \%{ }^{(5)}$. The significant values of specificity found in these studies represent the probability that cyanosis is absent in patients without the nursing diagnosis Impaired gas exchange. As previously reported, respiratory infections may compromise respiratory function and alveolar ventilation, leading to hypoxemia.

However, if it is not reversed, the patient may have cyanosis, which is a sign of greater severity. Regarding this, in the present investigation this characteristic was not evaluated separately, being considered present when the patient had peripheral and/or central cyanosis. Another point to be considered is that, although cyanosis was excluded from the last version of NANDA-I, the data from this research showed that it presents good specificity for this diagnosis. This result points out the need for new studies that evaluate its importance for the inference of the diagnosis Impaired gas exchange.

In the present investigation, the defining characteristic hypoxemia also presented high specificity, which diverged from another study ${ }^{(5)}$ performed with children with respiratory infections, in which hypoxemia presented the best accuracy measures to predict the occurrence of impaired gas exchange, with sensitivity of $96.5 \%$ and specificity of $98.3 \%$. The presence of hypoxemia in children with respiratory infection may be related to airway obstruction due to the accumulation of secretions, which may lead to changes in oxygen and carbon dioxide levels in the blood ${ }^{(16)}$. 
Importantly, if the airway obstruction effectively compromises gas exchange, causing changes in lung ventilation that interfere with the physiological functioning of the organism, the patient may present changes in mental state, such as restlessness, agitation, among others ${ }^{(16)}$. In this research, the defining characteristic restlessness presented low prevalence and high specificity. This result corroborates another study carried out with children with respiratory infections, which found specificity of $89.3 \%{ }^{(5)}$.

\section{Conclusion}

The most frequent defining characteristics of impaired gas exchange in children with respiratory diseases were dyspnea and tachycardia. As for the accuracy measurements, dyspnea and abnormal respiratory pattern presented high sensitivity values, while cyanosis, hypoxemia, and restlessness stood out because they presented greater specificity for this diagnosis.

\section{Acknowledgements}

To the Fundação de Amparo à Pesquisa e ao Desenvolvimento Científico e Tecnológico do Maranhão, process no. 00734/13.

\section{Collaborations}

Araújo AAO, Pascoal LM and Lopes MVO contributed to the conception, design, analysis, and interpretation of data. Gontijo PVC, Santos Neto M and Nunes SFL contributed in the writing of the article, critical review of the intellectual content, and final approval of the version to be published.

\section{References}

1. Pinto BF, Araújo PQ Amaral JDF. Atuação da fisioterapia no esforço respiratório em crianças hospitalizadas com infecção respiratória aguda: um estudo comparativo. Fisioter Br. 2017; 18(2):140-7. doi: http://dx.doi.org/10.33233/ fb.v18i2.791
2. Azevedo JVV, Alves TLB, Azevedo PV, Santos CAC. Influência das variáveis climáticas na incidência de infecção respiratória aguda em crianças no município de Campina Grande, Paraíba, Brasil. Rev Agrogeoambiental. 2014; 2:41-6. doi:http:// dx.doi.org/10.18406/2316-1817v0n02014742

3. Chaves DBR, Beltrão BA, Pascoal LM, Oliveira ARS, Andrade LZC, Santos ACB, et al. Defining characteristics of the nursing diagnosis "ineffective airway clearance". Rev Bras Enferm. 2016; 69(1):92-8. doi: http://dx.doi.org/10.1590/00347167.2016690114i

4. Lopes TAMC, Monteiro MDFV, Oliveira JD, Oliveira DR, Pinheiro AKB, Damasceno SS. Nursing diagnoses in hospitalized children. Rev Rene. 2017; 18(6):756-62. doi: dx.doi.org/10.15253/21756783.2017000600008

5. Pascoal LM, Lopes MVO, Chaves DBR, Beltrão BA, Silva VM, Monteiro FPM. Impaired gas exchange: accuracy of defining characteristics in children with acute respiratory infection. Rev Latino-Am Enfermagem. 2015; 23(3):491-9. doi: http:// dx.doi.org/10.1590/0104-1169.0269.2581

6. Gimenes FRE, Motta APG, Silva PCS, Gobbo AFF, Atila E, Carvalho EC. Identifying nursing interventions associated with the accuracy used nursing diagnoses for patients with liver cirrhosis. Rev Latino-Am Enfermagem. 2017; 25(2933):1-9. doi: dx.doi.org/10.1590/1518-8345.2016.2933

7. Herdman TH, Kamitsuru S. Diagnósticos de Enfermagem da NANDA-I: definições e classificação 2018-2020. Porto Alegre: Artmed; 2017.

8. Avena MJ,Pedreira MLG,GutiérrezMGR.Conceptual validation of the defining characteristics of respiratory nursing diagnoses in neonates. Acta Paul Enferm. 2014; 27(1):76-85. doi: http:// dx.doi.org/10.1590/1982-0194201400015

9. Ziegler B, Fernandes AK, Sanches PRS, Konzen GL, Dalcin PTR. Variabilidade da percepção da dispneia medida através de um sistema de cargas resistivas inspiratórias em indivíduos saudáveis. J Bras Pneumol. 2015; 41(2):143-50. doi: http://dx.doi. org/10.1590/S1806-37132015000004409

10. Qu Y, Tan M, Kutner MH. Random effects models in latent class analysis for evaluating accuracy of diagnostic tests. Biometrics [Internet]. 1996 [cited Feb. 20, 2019]; 52(3):797-810. Available from: https://www.jstor.org/stable/2533043 
11. Beath KJ. RandomLCA: an R package for latent class with random effects analysis. J Stat Softw. 2017; 81(13):1-25. doi: http://dx.doi.org/10.18637/jss. v081.i13

12. Pascoal LM, Lopes MVO, Silva VM, Chaves DBR, Beltrão BA, Nunes MM, et al. Clinical differentiation of respiratory nursing diagnoses among children with acute respiratory infection. J Pediatr Nurs. 2016; 31(1):85-91. doi: https://doi. org/10.1016/j.pedn.2015.08.002

13. Curley MAQ, Wypij D, Watson RS, Grant MJC, Asaro LA, Cheifetz IM, etal. Protocolized sedation vs usual care in pediatric patients mechanically ventilated for acute respiratory failure: a randomized clinical trial. JAMA. 2015; 313(4):379-89. doi: https://doi. org/10.1001/jama.2014.18399
14. Frauches DO, Lopes IBC, Giacomin HTA, Pacheco JPG, Costa RF, Lourenço CB. Doenças respiratórias em crianças e adolescentes: um perfil dos atendimentos na atenção primária em Vitória/ES. Rev Bras Med Fam Comunidade. 2017; 12(39):1-11. doi: https://doi.org/10.5712/rbmfc12(39)1450

15. Almeida AP, Cruz ICF. Patient diagnosed with impaired gas exchange-systematized literature review. J Specialized Nurs Care [Internet]. 2017 [cited Feb. 27, 2019];9(1). Available from: http:// www.jsncare.uff.br/index.php/jsncare/article/ view/2906

16. Caballero MT, Polack FP, Stein RT. Viral bronchiolitis in young infants: new perspectives for management and treatment. J Pediatr. 2017; 93: 75-83. doi: http://dx.doi.org/10.1016/j. jped.2017.07.003 